\title{
Preface: Giant jellyfish blooms in Chinese waters
}

\author{
Song Sun • Xiao-xia Sun • Ian R. Jenkinson
}

Received: 20 April 2015/Revised: 28 April 2015/Accepted: 29 April 2015/Published online: 29 May 2015

(C) Springer International Publishing Switzerland 2015

\begin{abstract}
The rationale, the design, and the methods that have been used in the Chinese National Basic Research Project on "Giant Jellyfish Blooms in Chinese Seas" are described. Sixteen papers resulting from the project are published in the present special issue, and these are individually addressed.
\end{abstract}

Keywords Chinese coastal seas · Jellyfish · Nemopilema $\cdot$ Rhopilema $\cdot$ Aurelia $\cdot$ Cymodocea

Guest editors: Song Sun, Xiao-xia Sun \& Ian R. Jenkinson / Giant Jellyfish Blooms and Ecosystem Change

S. Sun · I. R. Jenkinson ( ()

Key Laboratory of Marine Ecology and Environment, Institute of Oceanology, Chinese Academy of Sciences, 7, Nanhai Road, Qingdao 266071,

People's Republic of China

e-mail: ianjenkinson@qdio.ac.cn

S. Sun $\cdot X$. Sun

Jiaozhou Bay Marine Ecosystem Research Station, Institute of Oceanology, Chinese Academy of Sciences, 7, Nanhai Road, Qingdao 266071,

People's Republic of China

I. R. Jenkinson

Agency for Consultation and Research in Oceanography, 19320 La Roche Canillac, France

\section{Introduction}

Jellyfish blooms are perceived as increasing around the globe. Overall, jellyfish bring benefits as well as harm (Duarte et al., 2014). In East Asia, however, these blooms are considered the most serious ecological disaster, together with the harmful algae blooms (HABs), both of which are impacting the marine ecosystems, environmental safety, and the development of the maritime economy (Lucas et al., 2014).

Firstly, the occurrence of jellyfish blooms has been increasing in frequency and in geographical range, influencing the maritime economy in many ways. For example, commercial fishing is considerably impacted by aggregations of jellyfish (Lucas et al., 2014; Uye, 2014), increasing incidents of jellyfish stinging adversely influence coastal tourism, and jellyfish blooms at times block cooling systems in coastal factories, as well as those of nuclear power plants (Dong et al., 2014; Uye, 2014), causing significant economic losses.

Secondly, jellyfish blooms are changing the way marine ecosystems function. As top predators, once jellyfish become the dominant species in the ecosystem, they risk causing catastrophic regime shifts in the ecosystem, a subject that is much debated (Pauly et al., 1998; Condon et al., 2011, 2013).

Thirdly, jellyfish blooms are now a global issue. Because of their wide geographic range and serious consequences, jellyfish blooms have been one of the most sensitive and complex issues concerning 
ecological and environmental safety, and even international political cooperation. Therefore, amassing basic data on jellyfish blooms was required, so that these data can be used to understand the mechanisms and effects of bloom development and to address the above mentioned concerns.

A National Basic Research Program project on Giant Jellyfish Blooms in Chinese Seas was thus established for 2011-2015 by the Ministry of Science and Technology of the People's Republic of China. This overview gives the program structure and the methods used, as well as a brief overview of the principal findings published in this volume and elsewhere. Chinese seas principally affected are the Yellow Sea (YS), the East China Sea (ECS), and the
Bohai Sea (BH) (Fig. 1), which is where the National Program has been concentrated.

The key overall scientific aims of the Giant Jellyfish Bloom project ("Jellyfish Project") have been: (1) to understand the main controlling factors, key processes and driving mechanisms of jellyfish blooms in Chinese coastal waters; (2) to discover how jellyfish blooms influence the marine ecosystem and their mechanisms of causing harm; and (3) evaluating ecological disasters and discovering how to put in place mitigating measures.

The main specific aims of the Jellyfish Project have been to set up investigation of (1) life histories of the giant jellyfish species and the mechanisms by which environmental factors regulate the different developmental stages; (2) more specifically, how changes in
Fig. 1 The Bohai Sea, the Yellow Sea, and the East China Sea. From Wei et al. (2015), with permission. $K S W$ Kuroshio subsurface water; TWC Taiwan current, YSC Yellow Sea current, YSCWM Yellow Sea cold water mass, ZS Is Zhoushan Islands. (From Wei et al., 2015.)

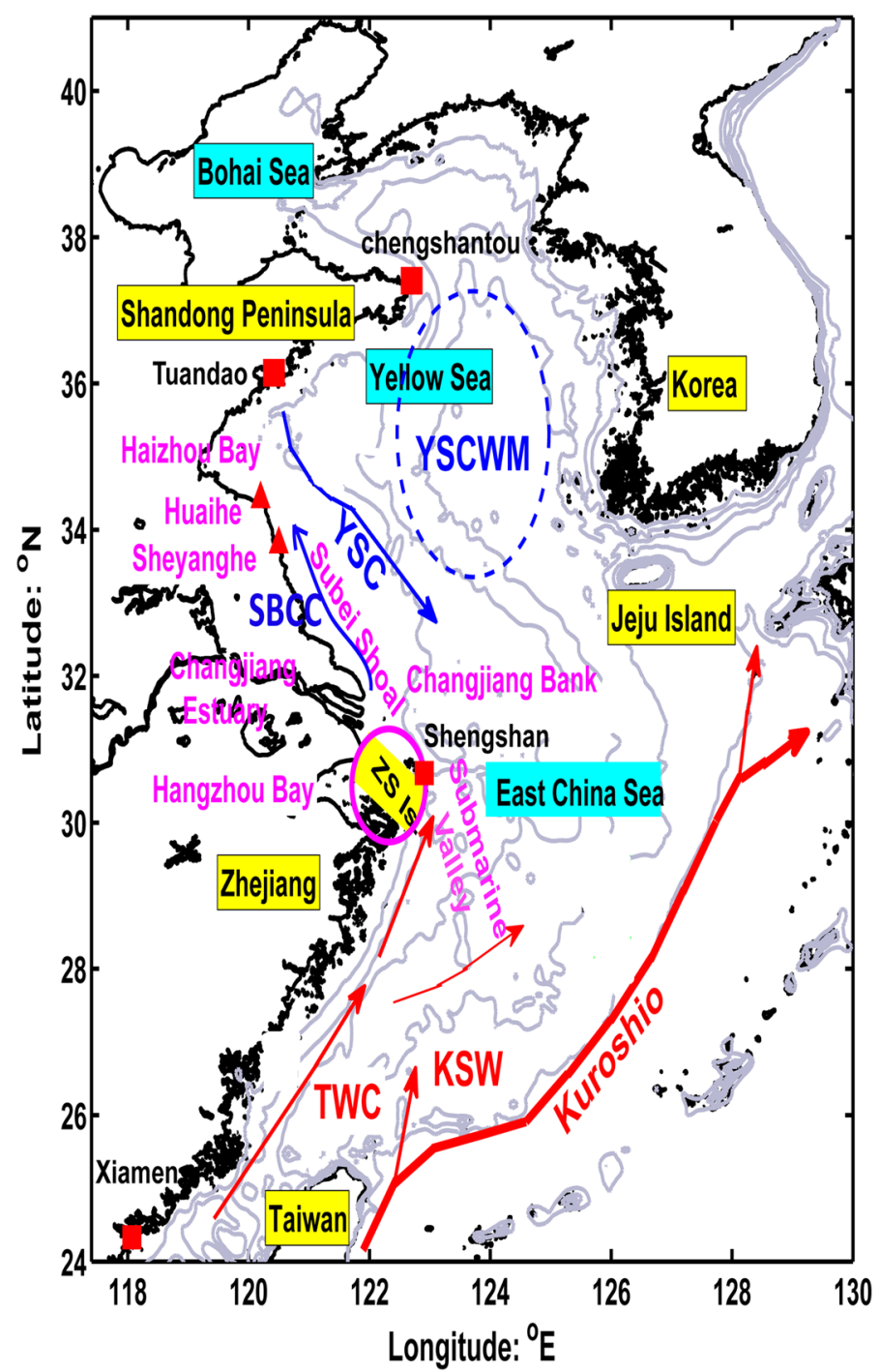


the marine environment and the food web control population growth in jellyfish; (3) ecological consequences and disaster-causing mechanisms of jellyfish blooms; and (4) the influence of jellyfish blooms on ecosystem succession in Chinese coastal waters, and what counter-measures to take.

This preface to the present special issue outlines the methods of putting these aims into practice, the principal findings (Results), and then discusses the findings in both the Chinese and the global context.

\section{Methods}

Figure 1 shows the study area; Fig. 2 illustrates the research scheme; Fig. 3 illustrates the approaches used; and Fig. 4 shows the research topics retained.

The project was also divided into six cross-cutting topics as follows:

Topic 1: life histories of bloom-forming jellyfish and the environmental mechanisms regulating their population growth

The research goals have been to detect the adaptation strategy and environmental requirements of the different developmental stages in the species' life history, and to measure basic time scales including development duration, growth rate, and mortality rate. Combining these with the results from the other five topics, especially the modeling study, we aim to understand their blooming and to predict how these factors will change in the future. This involves analyzing the processes, the main controlling factors, and the key events driving jellyfish blooms.

Topic 2: interactions between the marine environmental changes and jellyfish blooms

Based on the knowledge of hydrological dynamics and water-mass characteristics in the jellyfish blooming area, the research goals have been to understand the key biogeochemical processes governing the changes in nutrient levels on the structure, distribution, and succession of the local ecological community, to analyze how key environmental factors control the sensitive developmental stages of jellyfish, and finally to determine the inter-relations of jellyfish blooms with their driving factors.
Topic 3: inter-relationships

between phytoplankton community succession and jellyfish blooms

The research goals have been to elucidate the temporal and spatial changes and succession of the phytoplankton community, to reveal the connections between the population dynamics of the phytoplankton and zooplankton functional groups, and to understand the effect of jellyfish blooms on the composition and the structure of the phytoplankton community.

Topic 4: inter-relations between changes in zooplankton functional groups and jellyfish blooms

The research goals have been to study the interactions between jellyfish abundance and the zooplankton community structure, to elucidate the composition, distribution, and succession of zooplankton functional groups in the YS and the ECS, to measure the trophic contribution of zooplankton to the bloom-forming jellyfish, and to reveal the roles that zooplankton community succession plays during jellyfish population growth, as well as the controlling mechanisms and feedbacks.

Topic 5: inter-relationships between changes in jellyfish populations and both fish and benthos abundance

Focusing on the relationships between fishery resources and jellyfish population dynamics, the research goals have been to study the functional groups, as well as the distribution and succession of both the fish and benthos in the jellyfish blooming area, to measure the feeding connections among the fish, the benthos, and the jellyfish using controlled experiments aiming to reveal the responses and feedbacks among the fish and benthos functional groups to the jellyfish population dynamics.

Topic 6: ecological modeling study on both the mechanisms for jellyfish blooms and ecological consequences of these blooms

Using mathematical modeling, the research goal has been to study the spatial and temporal patterns using individual development and population dynamics in 
Fig. 2 Research scheme

\section{Research Scheme}

【 Disaster-causing mechanism \

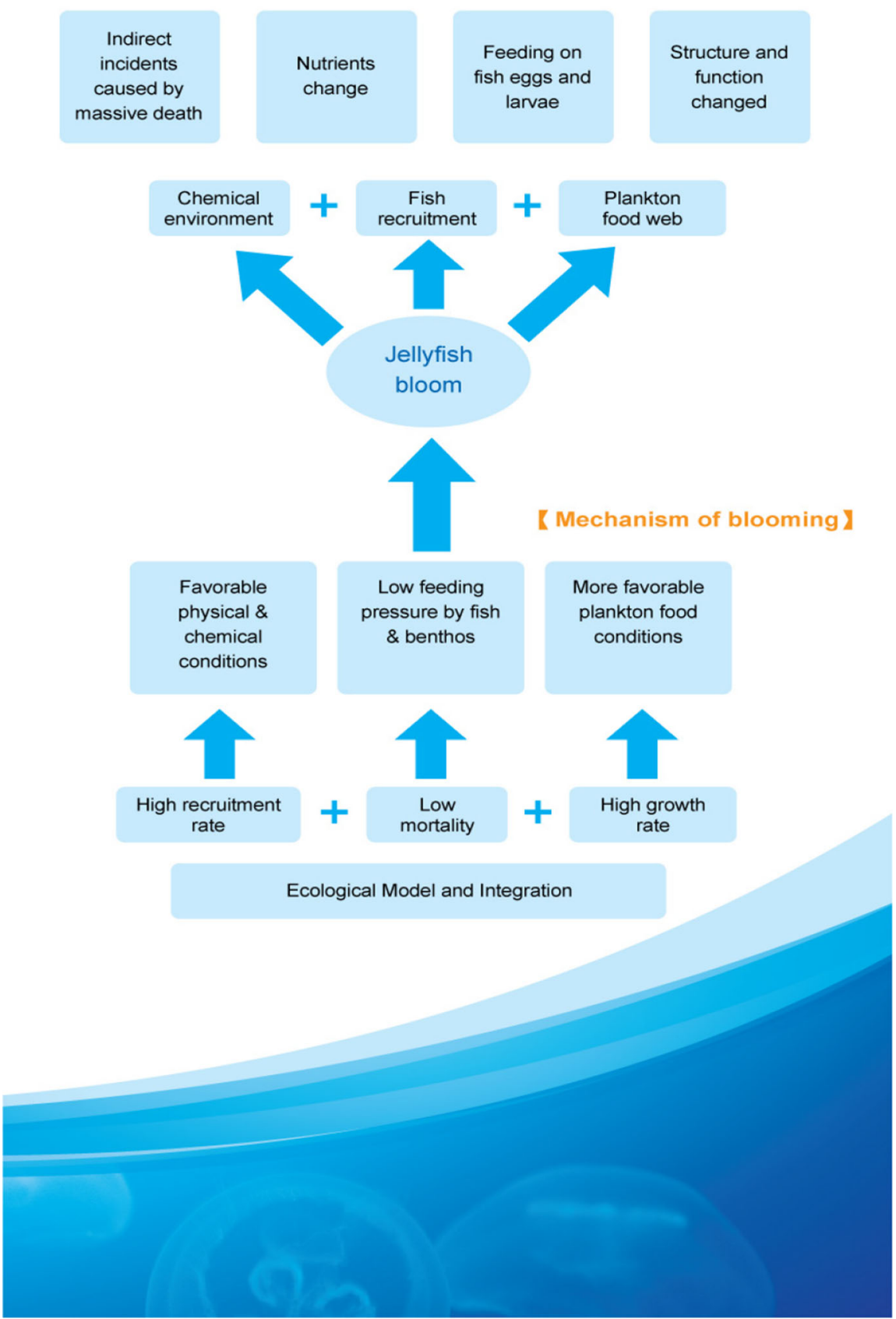

order to understand the mechanisms behind bloom development and to explore the possible ecological harm associated with variations in the environment and ecosystem caused by, as well as causing, jellyfish blooms. A further aim has been to establish a scientific basis for predicting consequent ecosystem changes, with a view to preventing possible ecological disasters and degradation. 
Fig. 3 Approaches used

\section{Approaches}

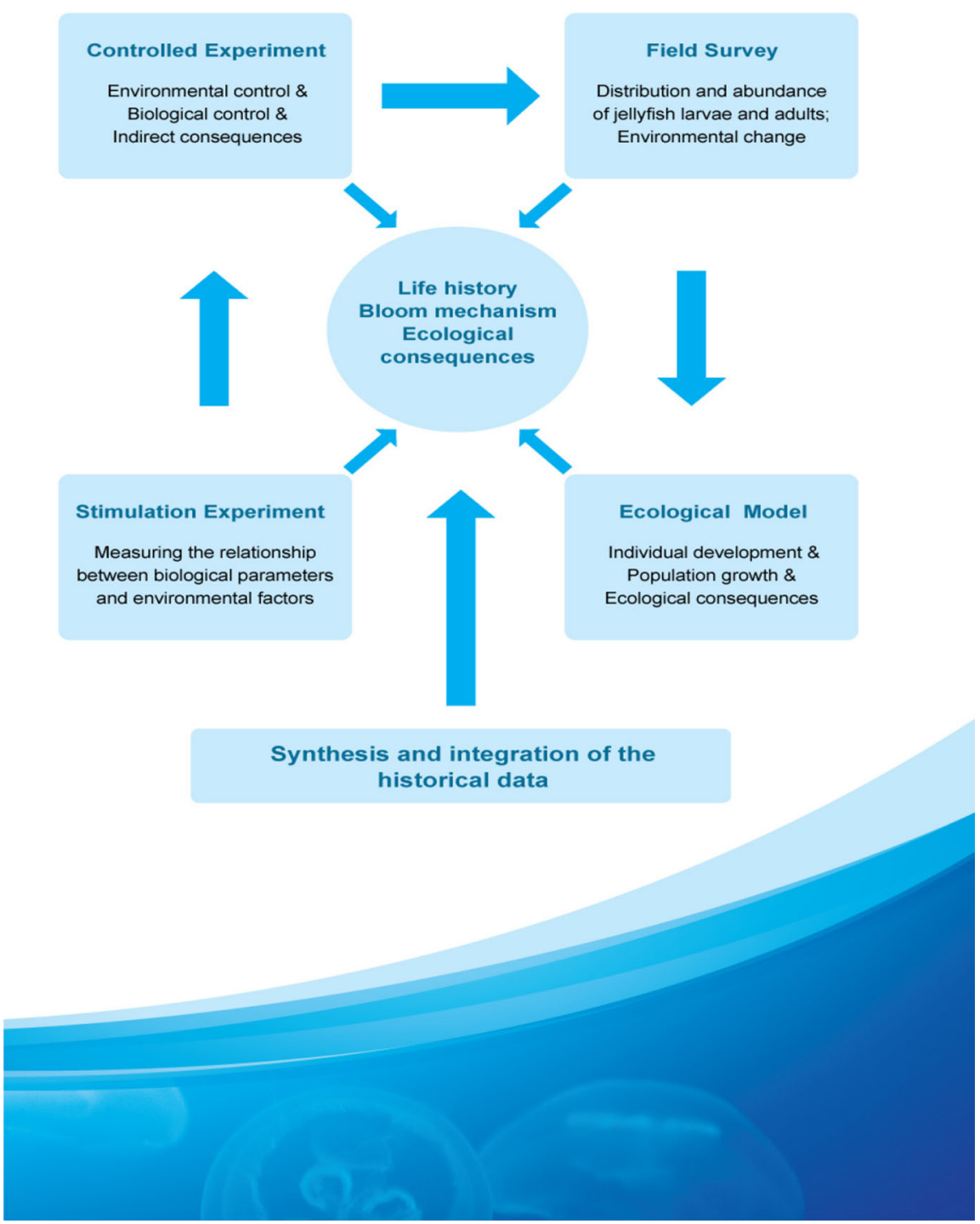

Research on background information relevant to understanding the ecosystem

In addition to research on the six topics above, this special issue presents newly researched background information about the $\mathrm{BH}$, the YS, and the ECS. It concerns variations in the salinity regime, phytoplankton response to different forms or organic phosphorus and the spatial distribution of different functional groups of mesozooplankton. Surveys of the benthos in the YS and the ECS done around the years 2000 and 2011 have also been compared.

\section{Results}

The environment

Bottom and surface salinity are important to jellyfish benthic and planktonic stages. Wei et al. (2015) 
Fig. 4 Research topics

\section{Research Topics}

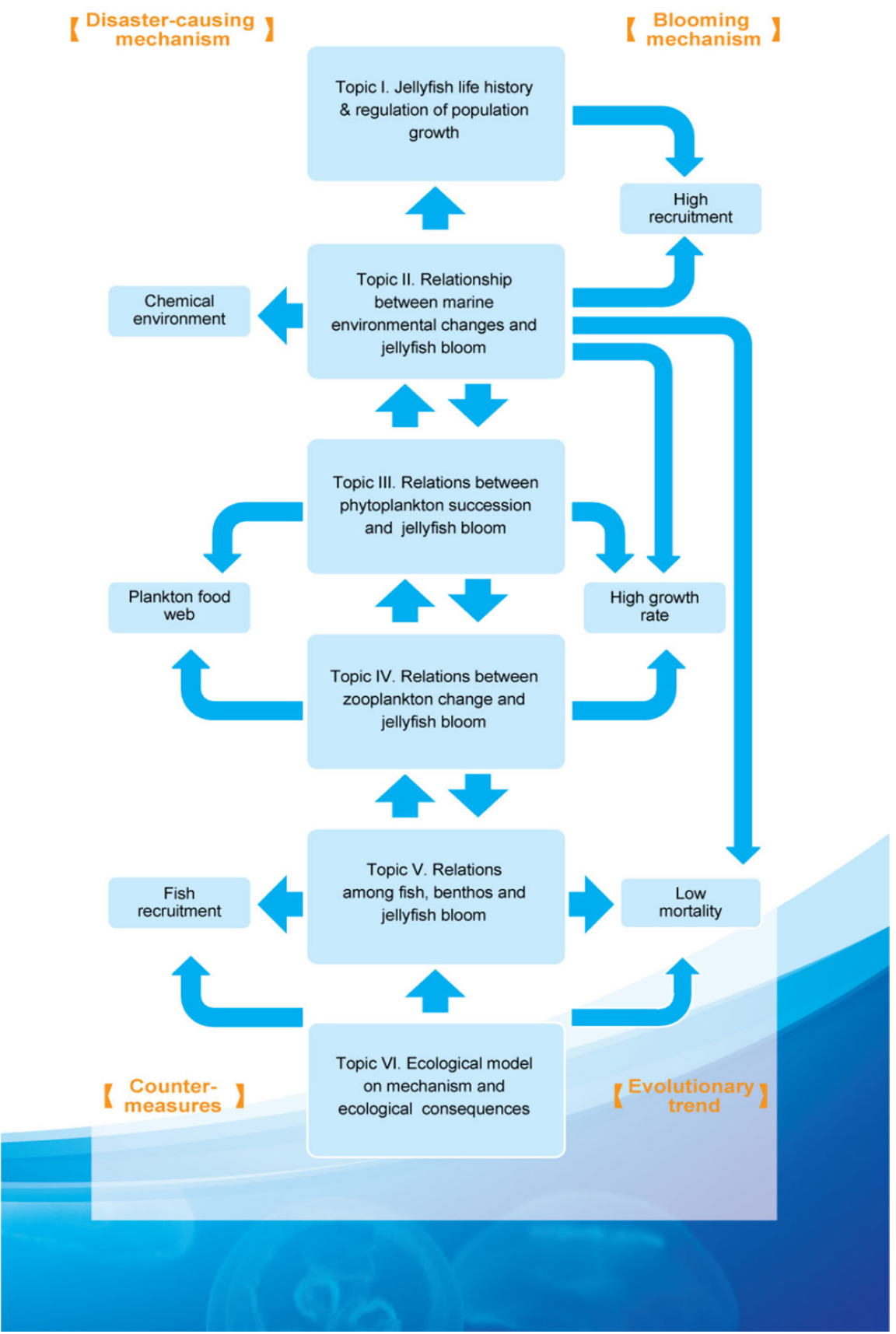

present observations of the salinity regime in the study area in the months of June to August in three consecutive years, 2011, 2012, and 2013, along with interannual variations in the currents, the wind, rainfall, river discharge, and hydrographic stratification. Along with atmospheric forcing and buoyancy input from rivers, the still little-understood variation in the Kuroshio Current, which powerfully meanders 
past the mouth of the ECS, and water-level discrepancy between the Bashi Channel and Taiwan Strait, are the main drivers of other currents in the ECS and the YS. By these mechanisms, they strongly influence both surface and bottom temperature and large salinity variations thereby undoubtedly circumscribing jellyfish population dynamics.

Phytoplankton is consumed by some stages in the life history of giant jellyfish. Over the last six decades and particularly the last two, coastal waters of China have been subject to a huge increase in the use of agricultural fertilizers, particularly N-based, increasing the inorganic $\mathrm{N}: \mathrm{P}$ ratio in the ECS and the YS, particularly near the coasts (Glibert et al., 2012). This has been associated with both increases in mean phytoplankton abundance and in blooms of algae including the diatom, Skeletonema costatum s.l., and the dinoflagellates, Prorocentrum donghaiense and Alexandrium catenella. Interactions among these and other HAB species have been much investigated, particularly in relation to this anthropogenic nutrient enrichment. Ou et al. (2015) have now shown that $A$. catenella outcompetes $P$. donghaiense in growth when inorganic $\mathrm{P}$ (P-inorg) is non-limiting, but when $\mathrm{P}$-inorg becomes limiting, $P$. donghaiense gains the advantage using organic $\mathrm{P}$, apparently facilitated by producing copious alkaline phosphatase, which, they found, A. catenella cannot do.

Zooplankton is a more major food item of giant jellyfish, particularly of the medusae. Shi et al. (2015) investigated the June distribution of six functional groups of zooplankton in the YS in three areas, west, middle, and east (respectively, WY, MY, and EY) at increasing distances east of the Chinese coast, over which water depths also increase. WY was in shallow water not over the Yellow Sea Cold Water Mass (YSCWM), MY was in water of intermediate depth over the edge of the YSCWM, and EY was in the deepest water and over the near-central parts of the YSCWM. The six functional groups studied were giant crustaceans (GC); large copepods (LC); small copepods (SC); chaetognaths (CH); medusae (ME); and salps (SA). The geographical distribution of the SC functional group was found to be associated with that of the giant jellyfish medusae, preferentially occurring in the MY area. The authors suggest that this is because giant jellyfish medusae feed preferentially on this functional group compared to the others. Sea bottom temperature and salinity, determined by the
YSCWM, are shown to have been major factors affecting the distribution of zooplankton functional groups. Additionally, the interannual biomass of SCs was positively related to temperature, and this may have restricted giant jellyfish outbreaks in cold years.

In 2000 and 2001, a considerable program of surveys of macrobenthos was made in the YS and the ECS (including the Changjiang Estuary). Included were species composition, taxon diversity, and organism size. A second major program of surveys of the area was carried out a decade later in 2011, and included most of the same stations sampled in 2000/2001. Comparisons between the two sets of surveys have been made by Li et al. (2014), and it is already clear that in the decade between the two programs, considerable degradation of the macrobenthos has occurred. Taxon diversity has markedly declined over the study area and so has overall organism size. This is ascribed to increased anthropogenic impacts. These impacts are considered to include coastal development, chemical pollution (including eutrophication), fishing pressure (particularly trawling), and extensive and expanding aquaculture.

\section{Nemopilema nomurai}

The giant jellyfish perceived as producing the most serious problems in Chinese, Japanese, and Korean waters is Nemopilema nomurai. It was even considered a threat to fisheries sustainability in East Asian marginal seas by Uye (2008), who also suggested that its occurrence in Japanese waters is largely owing to currents bringing them from nursery grounds in Chinese coastal waters, where environmental changes have caused their increase. Partly to elucidate this problem, Sun et al. (2015b) report surveys in 2012 and 2013 on the abundance and size distributions of medusae. These planktonic surveys were designed to pinpoint the distribution of the species' benthic stages, as well as providing information on its population dynamics. Results of surveys done in previous years were also reported. The Changjiang estuary offshore is now confirmed as one of the principal breeding places, and it is also the area where pelagic stages (medusae) appear the earliest in the YS and the ECS.

In the context of interannual temperature variations and global warming, two complementary studies are reported in this volume on the effects of previous-year temperature and feeding on development of polyps. 
Dong et al. (2015) report investigations of how salinity and light intensity affect growth and podocyst production in $N$. nomurai polyps. They found that variation in light had relatively minor effects. Salinity effects, however, were important, with the upper and lower survival limits for polyps of 10 and 40 psu respectively, while podocyst reproduction occurred best at salinities of 2-27.5 psu. The results indicate that $N$. nomurai polyps are adapted to grow and reproduce in estuaries and the near-shore environment.

To elucidate the effects of winter temperature on $N$. nomurai the following summer, Sun et al. (2015a) investigated the effect of exposing polyps for long durations to different low temperature and feeding frequencies, simulating different conditions of winter temperature and eutrophication. The results suggest that longer duration of low temperature in winter, followed by long periods at $10-13^{\circ} \mathrm{C}$, was the most favorable for development of strobila and hence for the production of medusae. Increasing food supply to the polyps also favored subsequent strobilation.

Song et al. (2015) investigated the effects of temperature and feeding on survival and growth on $N$. nomurai polyps. They showed that polyps can survive at temperatures from 0 to $27.5^{\circ} \mathrm{C}$ and can overwinter without feeding. Production and excystment of podocysts did not occur below $10^{\circ} \mathrm{C}$. Somatic growth, podocyst-formation, and excystment increased with increasing temperature and were dramatically affected by food supply at warmer temperatures. The authors suggest that high temperatures $\left(15-27.5^{\circ} \mathrm{C}\right)$ and abundant plankton biomass during the previous season should result in high productivity of polyps and significantly contribute to blooms of $N$. nomurai the following year.

\section{Cyanea nozakii}

This giant jellyfish occurs widely in the waters of China, Japan, and Korea. Like N. nomurai, it causes harm by clogging fishing nets, preying on juvenile fish and molluscs, and stinging swimmers. Moreover, it preys heavily on the edible and commercially important jellyfish Rhopilema esculentum, resulting, for example, in an estimated loss of 80 million US dollars in 2004 in the $\mathrm{BH}$ alone. Research on the life cycle and origin of this species has previously been hampered by the difficulty in obtaining and culturing their polyps in sufficient numbers. Here, Liu et al. (2015a) developed a method of culturing the species from fertilized eggs obtained from captured giant male and female medusae kept together, through the planula larva stage to produce copious polyps settled on easily handled artificial substrate. The authors further followed the development of the polyps through the production of ephyrae larvae and juvenile medusae. The techniques they developed should make it much easier to elucidate further details of the species' development and nutrition.

\section{Aurelia sp. 1}

The Scyphozoan jellyfish genus Aurelia is now considered to be cosmopolitan in distribution, while the Moon Jellyfish, formerly considered to be a single species Aurelia aurita, occurs widely in north and south temperate zones, as well as in Arctic waters. Recent work involving genomics (Dawson et al., 2005) strongly suggested that the taxon formerly known as A. aurita is really a species complex. Conveniently, the Moon Jellyfish in Chinese, Korean, and southern Japanese waters appears to be a single species, called Aurelia sp. 1 (Dawson et al., 2005), pending formal description and naming. The Aurelia species from Chinese waters investigated in this special issue can thus be assumed to be Aurelia sp. 1 , even though they have sometimes been referred to as "A. aurita."

In Chinese coastal waters, Aurelia sp. 1 occurs abundantly but appears to cause less dramatic problems than the other Scyphozoans, Nemopilema, or Cyanea. Aurelia sp. 1 is relatively easy to collect and to culture, and thus, research on this species is often less difficult and costly, yet can give information about its life cycle that is also relevant to that of other Scyphozoans.

Wang and Li (2015) investigated the effects of temperature and food concentration on the ontogeny of ephyrae. In an artificial long-term varying temperature regime designed to mimic that in the field, they found that strobilation occurs between 8 and $17^{\circ} \mathrm{C}$, with the optimal temperature at $13^{\circ} \mathrm{C}$. The authors concluded that abundant food in the field would promote larger bell diameters and a good nutritional foundation in the ephyrae and would increase survival rate and accelerate individual development. They thus suggest that a longer spring and 
abundant zooplankton food may increase blooms of Aurelia sp. 1, but that the ephyrae released in autumn and winter may contribute little to the following year's medusa population.

Wang et al. (2015b) compared how polyps reacted to being exposed to four harmful dinoflagellate species, a diatom and Artemia nauplii. They clearly performed best on Artemia nauplii, but feeding responses on the motionless diatoms were seldom seen. The polyps reacted to and ingested the two largest dinoflagellate species, A. catenella and Akashiwo sanguinea, but the two smallest, $P$. donghaiense and Karenia breve, were neither ingested nor apparently detected. Over a 91-day period, survival on phytoplankton was much less than on Artemia nauplii. High mortalities of the polyps given dinoflagellates suggest that blooms of these species in the field might harm them.

Cao et al. (2015) studied how Aurelia medusae preyed on fish larvae of the flounder. In particular, they found that predator size and temperature both affected predation rate and were correlated to the development stage of the fish larvae. It is concluded that Aurelia sp. 1 medusae are likely to impact recruitment of flounder along the northern Chinese coasts.

Wang and Sun (2015) investigated the population dynamics of Aurelia sp. 1 planktonic stages, ephyrae and medusae, from January to December 2011 in the inshore waters of Jiaozhou Bay, Qingdao. Ephyrae occurred from May to June, and young medusae were present from May 22, with maximum daily growth (bell diameter) of 39\%. Aurelia sp. 1 abundance had become very low by September, and they disappeared soon after.

Wang et al. (2015a) investigated the effects of temperature and food concentration on budding and strobilation in polyps. The "preparation period" before strobilation decreased as temperature increased but was not observed to be affected by food concentration $\left(0-0.1 \mathrm{mg} \mathrm{C}^{-1}\right)$. Over the range of temperatures tested, $13^{\circ} \mathrm{C}$ was found to be the best for release of ephyrae, while $15^{\circ} \mathrm{C}$ was best for bud production. The results suggest that increasing eutrophication would increase the abundance of both polyps and juvenile medusae. Temperature, on the other hand, may adjust the reproductive energy distribution between budding and ephyra release, thus helping match the production of juvenile medusae to the peak of zooplankton biomass.
Huang et al. (2015) investigated the effects of temperature and food type (a dinoflagellate, a diatom, zooplankton (Artemia nauplii), and no food) on asexual reproduction in Aurelia polyps. A reduction in temperature from 20 to 15 or $10^{\circ} \mathrm{C}$ induced release of ephyrae but only when food was present. When provided with Artemia nauplii, the polyps reproduced more by budding, by podocyst production and by strobilation, than with the other treatments. At temperatures of $20^{\circ} \mathrm{C}$ or more, mortality of polyps exceeded 50\% except when given Artemia nauplii. The authors conclude that when animal prey is limited, plants can serve as a nutrient source and satisfy the energy requirements of Aurelia sp. 1 at lower temperatures. However, phytoplankton cannot provide adequate nutrition at temperatures of $20^{\circ} \mathrm{C}$ or more. Abundant animal prey and suitable temperatures are essential conditions for polyps to strobilate and release ephyrae, potentially leading to jellyfish blooms.

Rhopilema and Aurelia in finfish culture

Liu et al. (2015b) compared two giant jellyfish species in Chinese waters, R. esculentum and Aurelia sp. 1, as food for rearing commercial fish, the silver pomfret, Pampus argenteus. Detailed nutritional analysis of both jellyfish was also carried out. It was concluded that both jellyfish species could be used as food for these fish and could be used as an important complement to current commercial food. This might provide an economic incentive to fish down harmful giant jellyfish blooms in Chinese waters.

\section{Reproduction in Cyanea and Nemopilema}

Finally, responses to temperature (five treatments) and food supply (three treatments) of asexual reproduction by polyps of $C$. nozakii and $N$. nomurai were compared by Feng et al. (2015) in a balanced set of culture experiments up to 100 days long. The aim was to investigate how these two species might react to future change in temperature and zooplankton abundance over the year. The results of the study suggest that the response of asexual response to ocean warming will be species specific. In summer and autumn during warm years, increased ephyra production in C. nozakii, but higher podocyst production in $N$. nomurai, is to be expected. 


\section{Discussion}

Extensive discussions of the results of the National Basic research Project on Chinese Giant Jellyfish Project are to be found in each of the papers that the project has produced, published both in the present volume and elsewhere. More far-ranging discussion will take place as part of international scientific meetings and collaboration. In this respect, we hope that our colleagues worldwide will find this volume useful to help understand our jellyfish blooms as well as those in their own waters. Ocean ecosystems will inexorably change in the years to come, as they respond to outside forcing and their internal dynamics. We hope that this volume will contribute to a body of knowledge that will help scientists, environmental managers, and other informed people with the difficult task of guiding respectful interaction with ocean ecosystems, anticipating and dealing with problems, smoothing the path, and avoiding disasters.

Acknowledgments This work was supported by the Project "The Key Processes, Mechanism and Ecological Consequences of Jellyfish Bloom in China Coastal Waters"(Grant No. 2011CB403600). Finally, we thank Hydrobiologia, Springer Publishing Group, and particularly Professor Koen Martens for working with us closely to put this volume together.

\section{References}

Cao, L., J. Liu, X. Yu, B. Zhao, X. Shan, Z. Zhuang \& S. Dou, 2015. Size-dependent predation of fish larvae by jellyfish: an experimental evaluation exemplified with the flounder Paralichthys olivaceus larvae and the moon jellyfish Aurelia aurita medusae. Hydrobiologia, this issue. doi:10. 1007/s10750-014-1984-4.

Condon, R. H., D. K. Steinberg, P. A. del Giorgio, T. C. Bouvier, D. A. Bronk, W. M. Graham \& H. W. Ducklow, 2011. Jellyfish blooms result in a major microbial respiratory sink of carbon in marine systems. Proceedings of the National Academy of Sciences of the United States of America 108: 10225-10230.

Condon, R. H., C. M. Duarte, K. A. Pitt, K. L. Robinson, C. H. Lucas, K. R. Sutherland, H. W. Mianzan, M. Bogeberg, J. E. Purcell, M. B. Decker, S.-I. Uye, L. P. Madin, R. D. Brodeur, S. H. D. Haddock, A. Malej, G. D. Parry, E. Eriksen, J. Quiñones, M. Acha, M. Harvey, J. M. Arthur \& W. M. Graham, 2013. Recurrent jellyfish blooms are a consequence of global oscillations. Proceedings of the National Academy of Sciences of the United States of America 110: 1000-1005.

Dawson, M. N., A. Sen Gupta \& M. H. England, 2005. Coupled biophysical global ocean model and molecular genetic analyses identify multiple introductions of cryptogenic species. Proceedings of the National Academy of Sciences of the United States of America 102: 11968-11973.

Dong, J., M. Sun, J. E. Purcell, Y. Chai, Y. Zhao \& A. Wang, 2015. Effect of salinity and light intensity on somatic growth and podocyst production in polyps of the giant jellyfish Nemopilema nomurai (Scyphozoa: Rhizostomeae). Hydrobiologia, this issue. doi:10.1007/s10750014-2087-y.

Dong, Z., D. Liu \& J. K. Keesing, 2014. Contrasting trends in populations of Rhopilema esculentum and Aurelia aurita in Chinese waters. In Pitt, K. A. \& C. H. Lucas (eds), Jellyfish Blooms. Springer, Dordrecht: 207-218.

Duarte, C. M., K. A. Pitt \& C. H. Lucas, 2014. Introduction: understanding jellyfish blooms. In Pitt, K. A. \& C. H. Lucas (eds), Jellyfish Blooms. Springer, Dordrecht: 1-5.

Feng, S., G.-T. Zhang, S. Sun, F. Zhang, S. W. Wang \& M.-T. $\mathrm{Li}, 2015$. Effects of temperature regime and food supply on asexual reproduction in Cyanea nozakii and Nemopilema nomurai. Hydrobiologia, this issue. doi:10.1007/s10750015-2279-0.

Glibert, P. M., J. M. Burkholder \& T. M. Kana, 2012. Recent insights about relationships between nutrient availability, forms, and stoichiometry, and the distribution, ecophysiology, and food web effects of pelagic and benthic Prorocentrum species. Harmful Algae 14: 231-259.

Huang, X.-G., B. Huang, Y. Zeng \& S.-X. Li, 2015. Effect of dinoflagellates and diatoms on the feeding response and survival of Aurelia sp. polyps. Hydrobiologia, this issue. doi:10.1007/s10750-014-2023-1.

Li, X.-Z., H.-F. Wang, J.-B. Wang, D. Dong, L. Ma, Q. Kou, J.X. Sui, Z.-B. Gan \& B.-L. Zhang, 2014. Biodiversity variability of macrobenthic in the Yellow Sea and East China Sea between 2001 and 2011. Zoological Systematics 39: 459-484.

Liu, C.-S., Z.-M. Zhuang, S.-Q. Chen, J.-P. Yan, C.-L. Liu \& J.M. Sun, 2015a. A large-scale breeding experiment and observations on development of Cyanea nozakii (Scyphozoa, Cyaneidae) from fertilized eggs to larval medusae. Hydrobiologia, this issue. doi:10.1007/s10750-014-18838.

Liu, C.-S., S.-Q. Chen, Z.-M. Zhuang, J.-P. Yan, C.-L. Liu \& H.T. Cui, 2015b. Potential of utilizing jellyfish as food in culturing Pampus argenteus juveniles. Hydrobiologia, this issue. doi:10.1007/s10750-014-1869-6.

Lucas, C. H., S. Gelcich \& S.-I. Uye, 2014. Living with jellyfish: management and adaptation strategies. In Pitt, K. A. \& C. H. Lucas (eds), Jellyfish Blooms. Springer, Dordrecht: 129-150.

Ou, L., X. Huang \& B. Huang, 2015. Growth and competition for different forms of organic phosphorus by the dinoflagellate Prorocentrum donghaiense with the dinoflagellate Alexandrium catenella and the diatom Skeletonema costatum s.l. Hydrobiologia, this issue. doi:10.1007/s10750-014-1994-2.

Pauly, D., J. Christensen, R. Dalsgaard, R. Froese \& F. Torres, 1998. Fishing down marine food webs. Science 279: 860-863.

Shi, Y.-Q., S. Sun \& G.-T. Zhang, 2015. Distribution pattern of zooplankton functional groups in the Yellow Sea in June: a possible cause for geographical separation of giant jellyfish species. Hydrobiologia, this issue. doi:10.1007/s10750014-2070-7. 
Song, F., F. Zhang, S. Sun, S. Wang \& C. Li, 2015. Effects of duration at low temperature on asexual reproduction in polyps of the scyphozoan Nemopilema nomurai (Scyphozoa: Rhizostomeae). Hydrobiologia, this issue. doi: 10 . 1007/s10750-015-2173-9.

Sun, M., J. Dong, J. E. Purcell, Y. Li, Y. Duan, A. Wang \& B. Wang, 2015a. Testing the influence of previous-year temperature and food supply on development of Nemopilema nomurai blooms. Hydrobiologia, this issue. doi:10.1007/ s10750-014-2046-7.

Sun, S., F. Zhang, C. Li, S. Wang, M. Wang, Z. Tao, Y. Wang, G. Zhang \& X. Sun, 2015b. Breeding places, population dynamics and distribution of the giant jellyfish Nemopilema nomurai (Scyphozoa: Rhizostomeae) in the Yellow Sea and the East China Sea. Hydrobiologia, this issue. doi:10. 1007/s10750-014-2266-5.

Uye, S., 2008. Blooms of the giant jellyfish Nemopilema nomurai: a threat to the fisheries sustainability of the East Asian Marginal Seas. Plankton and Benthos Research 3(Suppl.): 125-131.

Uye, S., 2014. The giant jellyfish Nemopilema nomurai in East Asian marginal seas. In Pitt, K. A. \& C. H. Lucas (eds), Jellyfish Blooms. Springer, Dordrecht: 185-205.
Wang, N. \& C. Li, 2015. The effect of temperature and food supply on the growth and ontogeny of Aurelia sp. 1 ephyrae. Hydrobiologia, this issue. doi:10.1007/s10750014-1981-7.

Wang, N., C. Li, Y. Liang, Y. Shi \& J. Lu, 2015a. Prey concentration and temperature effect on budding and strobilation of Aurelia sp. 1 polyps. Hydrobiologia, this issue. doi:10.1007/s10750-014-1994-2.

Wang, Y.-T. \& S. Sun, 2015. Population dynamics of Aurelia sp. 1 ephyrae and medusae in Jiaozhou Bay, China. Hydrobiologia, this issue. doi:10.1007/s10750-014-2021-3.

Wang, Y.-T., S. Zheng, S. Sun \& F. Zhang, 2015b. Effect of temperature and food type on asexual reproduction in Aurelia sp. 1 polyps. Hydrobiologia, this issue. doi:10. 1007/s10750-014-2020-4.

Wei, H., X. Luo \& Y. Zhao, 2015. Intraseasonal variation in the salinity of the Yellow and East China Seas in the summers of 2011, 2012, and 2013. Hydrobiologia, this issue. doi: 10 . 1007/s10750-014-2133-9. 